
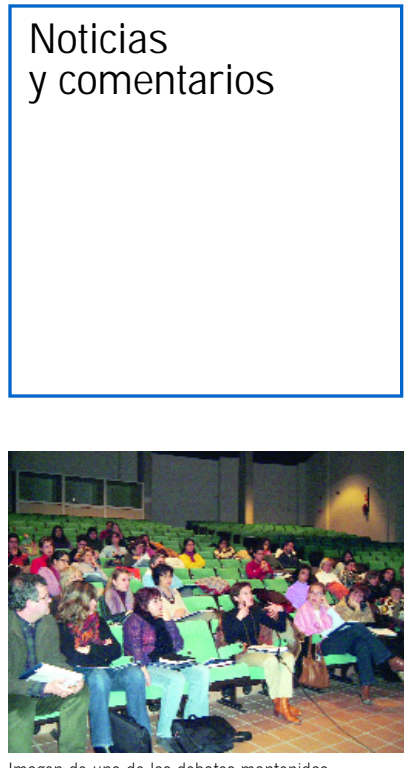

Imagen de uno de los debates mantenidos

\title{
Nuevos enfoques en arqueología reclaman el protagonismo de la mujer en las sociedades prehistóricas
}

El curso "Arqueología y género: vida cotidiana, relaciones e identidad", celebrado en la Facultad de Filosofía y Letras de la Universidad de Granada entre los días 7 y 11 de marzo de 2005 y organizado por el Departamento de Prehistoria y Arqueología y el Instituto Universitario de Estudios de la Mujer de esta misma universidad, surgió por dos motivaciones fundamentales: la buena acogida obtenida por la primera edición del curso (marzo de 2003, ver $\mathrm{PH}$ 44) y nuestro convencimiento de que aún se mantienen las condiciones que motivaron el primer encuentro, es decir, que muchas de las ideas que se usan para justificar la desigualdad entre mujeres y hombres están basadas en asunciones preconcebidas y sin ningún valor crítico, programadas e instituidas desde mucho tiempo atrás por quienes han construido y escrito la historia. Este hecho es especialmente visible en el estudio de las sociedades prehistóricas, en las que debido a una supuesta objetividad se ha conseguido que el modelo que observamos sea el del adulto, masculino, blanco y occidental, que constituye la norma, mientras que el resto de la población, fundamentalmente mujeres e individuos infantiles, pasan a ser lo anecdótico, al ser eliminada cualquier relevancia que pudiera constatar su papel fundamental para el desarrollo de estas sociedades.

A estas cuestiones se une además el hecho de que desde los departamentos de Prehistoria y Arqueología de las distintas universidades andaluzas no se ha considerado la investigación sobre las mujeres en la prehistoria como suficientemente interesante como para darle cabida en los diseños curriculares de las enseñanzas universitarias; de hecho, únicamente algunos cursos especializados de tercer ciclo y jornadas programadas desde otras universidades la incluyen en sus programas este debate. Así, el alumnado universitario que cursa estudios de historia percibe la prehistoria como un tiempo masculino en el que las mujeres no tienen cabida, repitiendo constantemente los modelos planteados en el XIX. En este contexto se programó la realización de un curso que facilitara al alumnado universitario la posibilidad de aproximarse a esta perspectiva de investigación histórica y plantear y debatir otras posibilidades de interpretación del registro arqueológico; la metodología propuesta era mirar a las mujeres y sus relaciones, trabajos, actividades y rituales para hacerlas visibles, valorando en todo momento su verdadero e indispensable papel en el desarrollo de las sociedades de la Prehistoria y permitiendo mediante su conocimiento acercarnos desde otra perspectiva a las sociedades prehistóricas. Este año además hemos considerado la importancia de la edad en los debates sobre las sociedades de la antigüedad, ya que si el tema de las mujeres ha sido muy poco abordado, el de los individuos infantiles y los mayores ha sido aún más escasamente tratado.

Afortunadamente, la inclusión del análisis de género en la arqueología de nuestro país es cada vez más frecuente, gracias al trabajo de mujeres arqueólogas y profesoras universitarias que han asumido y enriquecido en los últimos años el desarrollo conceptual y metodológico elaborado en otras disciplinas. Este hecho ha quedado reflejado en el desarrollo del curso.

Los temas tratados pueden ser incluidos en los siguientes apartados: Origenes de la sexualidad humana (Manuel Domínguez Rodrigo, UCM); El poder, las mujeres y los hombres durante la Prehistoria (Almudena Hernando Gonzalo, UCM); La mujer representada: de las figurillas paleolíticas y las "damas" ibéricas a las imágenes en la actualidad (Cristina Masvidal Fernández, UAB; Trinidad Escoriza Mateu, U. Almería; Carmen Aranegui Gascó, U. Valencia; Teresa Orozco Köhler, U. Valencia); Vida cotidiana en la Prehistoria: objetos, espacios y relaciones (Sandra Montón Subias, Paloma González Marcén, UAB y Marina Picazo, U. Pompeu Fabra; Encarna Sanahuja YII, UAB; Carmen Risquez y Carmen Rueda Galán, U. Jaén); El trabajo de las mujeres: los lugares de encuentro y producción ( $\mathrm{M}^{\mathrm{a}}$ Dolores Mirón, U. Granada); Las mujeres y la muerte en la cultura ibérica (Isabel Izquierdo Peraile, Ministerio de Cultura); La mujer sacralizada: rituales y santuarios en época ibérica (Antonia García Luque, U. Jaén; Lourdes Prados Torreira, UAM y Trinidad Tortosa Rocamora, Instituto de Arqueología de Mérida, CSIC) y finalmente, Mujeres en relación: el análisis de la maternidad y la infancia durante la Prehistoria (Teresa Chapa Brunet, UCM; Margarita Sánchez Romero, U. Granada).

Además se incluyeron como actividades del curso la exposición Arqueología en clave de género, con fotografías de María Cristina Fernández-Laso, investigadora del Área de Prehistoria de la Universidad Rovira y Virgili de Tarragona y de Raquel Platero, investigadora en Género y Políticas Públicas, de la UCM, mostrando los trabajos realizados en los yacimientos de la Sierra de Atapuerca (Burgos) y en el yacimiento Abrí Romaní (Capellades, Barcelona). Igualmente se realizó la presentación del libro Saguntum; oppidum, emporio y municipio romano, de Carmen Aranegui Gascó.

Margarita Sánchez Romero Francisco Contreras Cortés Dpto. de Prehistoria y Arqueología Universidad de Granada 